\title{
Implementación de una WSN flexible para aplicaciones en la vigilancia del medio ambiente
}

\author{
D. Antolín, A. Bayo, N. Medrano, B. Calvo, S. Celma \\ Grupo de Diseño Electrónico (GDE) \\ Instituto de Investigación en Ingeniería de Aragón (I3A) \\ Universidad de Zaragoza, Pedro Cerbuna 12, 50009, Zaragoza, Spain. \\ Tel.+34-976762143, e-mail:dantolin@unizar.es
}

\begin{abstract}
El uso de redes de sensores inalámbricos para la monitorización de parámetros físicos y químicos en grandes áreas y lejos de las poblaciones permite la monitorización en tiempo real con un alto nivel de resolución espacial. Este trabajo presenta el desarrollo de una red inalámbrica de sensores diseñada para la toma de medidas de parámetros físicos en regiones extensas. Dependiendo de las infraestructuras disponibles, la red puede transmitir los datos directamente a un ordenador personal que se encargue de su posterior tratamiento, o a través de un nodo sensor conectado a un módulo GSM/GPRS o mediante un teléfono por satélite como los Inmarsat o Iridium. Posteriormente, este nodo enviará mediante SMS la información recogida por la red a la estación central de procesamiento donde la información será procesada. La red puede funcionar de forma autónoma durante dos años utilizando únicamente las baterías si se emplean un conjunto de sensores estándar, si bien se está trabajando en el desarrollo de un sistema de carga de baterías mediante paneles solares utilizando métodos de seguimiento del punto de máxima potencia para optimizar la eficiencia del sistema.
\end{abstract}

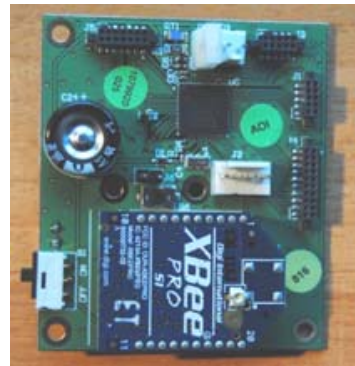

(a)

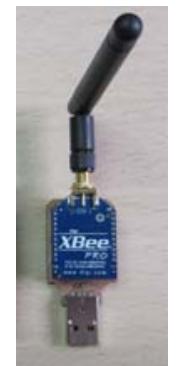

(b)

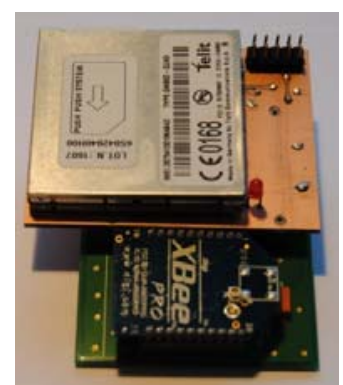

(c)

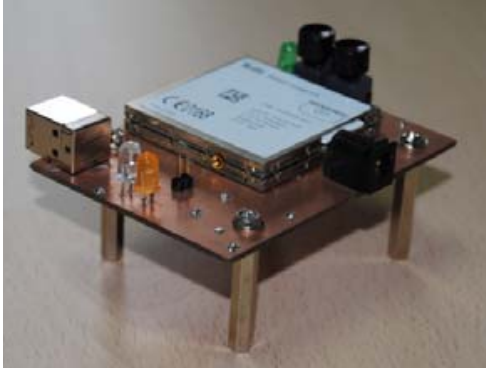

(d)

Figura 1. Módulos desarrollados: (a) nodo sensor; (b) módulo adaptador 802.15.4 - usb para PC; (c) Nodo sensor con módulo GSM y (d) módulo receptor GSM para PC 